Full-text Available Online at www.ajol.info and www.bioline.org.br/ja
J. Appl. Sci. Environ. Manage. March 2014

Vol. 18 (1) 135-140

\title{
Suitability of Moshi Pumice for Phosphorus Sorption in Constructed Wetlands
}

\section{$*^{1}$ ANESI S. MAHENGE}

Environmental Engineering Department, Ardhi University (ARU), P.O.Box 35176, Dar-es-Salaam, Tanzania, Cell: +255-762-279612

KEYWORDS: Phosphorus sorption; Sorption Equilibrium; Sorption Models; Behaviours and Properties.

\begin{abstract}
The study of Moshi Pumice's phosphorus sorption behaviours and properties was carried out in laboratory scale where by $1-2 \mathrm{~mm}, 2-4 \mathrm{~mm}$ and $4-8 \mathrm{~mm}$ grains were tested using batch experiments. The results show that Moshi Pumice has high phosphorus sorption capacity. The sorption capacity for the Moshi Pumice was $2.5 \mathrm{~g} \mathrm{P} / \mathrm{kg}$. For 1-2mm and 4$8 \mathrm{~mm}$ grains; about 50\% of phosphorus sorption in Moshi Pumice occurs in the first 18 and 20 hours, respectively. Compared to $4-8 \mathrm{~mm}$ and $2-4 \mathrm{~mm}$ grains, temperature didn't significantly influence phosphorus sorption on $1-2 \mathrm{~mm}$ grain. Moshi Pumice has high potential for phosphorus removal from wastewaters and it can be recommended to be used as a substrate in constructed wetlands to remove phosphorus. (C) JASEM
\end{abstract}

http://dx.doi.org/10.4314/jasem.v18i1.19

Introduction: Phosphorus (P) is an essential macronutrient in all organisms. However, loadings of phosphorus in effluent discharges are detrimental to the quality of receiving surface water bodies. Phosphorus concentrations in excess of allowable levels have been associated with algal blooms, which lead to the eutrophication of lakes and rivers. Eutrophication occurs when surface waters become over-enriched with nutrients such as nitrogen and phosphorus. This stimulates plant and algal growth, which subsequently dies and decomposes; thereby reducing, dissolved oxygen concentrations in water columns, which is detrimental to aquatic life. For this reason, the treatment of wastewater is necessary to correct its characteristics in such a way that the use or final disposal of treated effluent can take place without causing an adverse impact on the ecosystem of the receiving water bodies (Headley et al, 2001).

Subsequently, many technologies in association with management systems have been devised both to prevent and mitigate the loss of phosphorus, which can cause eutrophication of surface waters. One approach, which is a land-based ecologically engineered method, is the use of wetlands. Wetland ecosystems both constructed and natural are becoming important mitigating measures in water resource management around the world, as they have the ability to cycle and retain nutrients such as phosphorus (Braskerud, 2002).
Phosphorus removal in wetlands mainly occurs by sorption and plant uptake. Phosphorus sorption in wetland substrates occurs by adsorption and precipitation. Phosphorus retention in the substrate via adsorption and precipitation is controlled by properties of the substrate (Fe, $\mathrm{Mg}, \mathrm{Al}-, \mathrm{Ca}$-minerals, specific surface area and porosity) and the physicochemical environment $(\mathrm{pH}$, redox potential, dissolved ions) (Grüneberg and Kern, 2001).

Wetland substrates (e.g. clay, soil, gravel) for wastewater treatment are normally not considered efficient for continual removal of phosphorus. Phosphorus removal above $20-30 \%$ in long-term monitoring (> 5 years) is seldom reported. So, inorder to achieve high phosphorus removal, specialized substrates which are effective in sorption of phosphorus like granite, limestone, metal oxiderich natural sands, mining industry by-products and slags (Salnacke, 1999) are to be used in a subsurface flow constructed wetland or in a vertical flow column. The capacity for phosphorus sorption is finite in all media and longevity with respect to phosphorus sorption depends on the loading rates. The design regarding phosphorus removal in substrates with high phosphorus sorption is quite different from other water quality parameters, the intention being to exhaust a short-term capacity, regenerate the filter and repeat the cycle (Braskerud, 2002). 
Moshi Pumice is a substrate that is rich in minerals that facilitate sorption of phosphorus. Test results have shown that Moshi Pumice substrate has a high potential for phosphorus removal compared to granite, gravel and clay soil (Njau et al, 2002). However, little is known about its behaviours and properties in sorption of phosphorus and its potential for the use as constructed wetland substrate.

\section{MATERIALS AND METHODS}

Moshi Pumice is the material (substrate) used in this study. It is a potential filter media in constructed wetlands. It is a porous and volcanic, found near the slopes of Mount Kilimanjaro, collected from a village known as Uchira about $15 \mathrm{~km}$ from Moshi town.

The chemical composition of Moshi Pumice was analyzed by X-ray fluorescence (XRF) technique. Crushed soil particles of less than $420 \mu \mathrm{m}$ were dried in an oven at $110^{\circ} \mathrm{C}$ to determine moisture content. A known weight of the dried sample was used to determine loss on ignition at $1,100^{\circ} \mathrm{C}$. The calcined sample was mixed with sodium borohydrate at a ratio of 1:9 w/w, respectively. The mixture was melted to obtain the specimen disc for the XRF analysis. The porosity and the specified surface area of the substrate was measured by the Brunauer Emmett and Teller (BET) standard method for particle sizes ranging from $125 \mu \mathrm{m}<\mathrm{d}<420 \mu \mathrm{m}$. The particle density of the substrate was measured by displacing water by a known mass using stopped bottle. Particle sizes less than $420 \mu \mathrm{m}$ were used.

\section{Study of Phosphorus Sorption Behaviours:} Phosphorus sorption experiments in batch experiments were carried out at ambient temperature with a slow rotating shaker $(25 \mathrm{rpm})$ to avoid material alteration as shown in plate 1. Only one experiment was carried out for each sorption behaviour experiment and four samples of each experiment were analyzed.

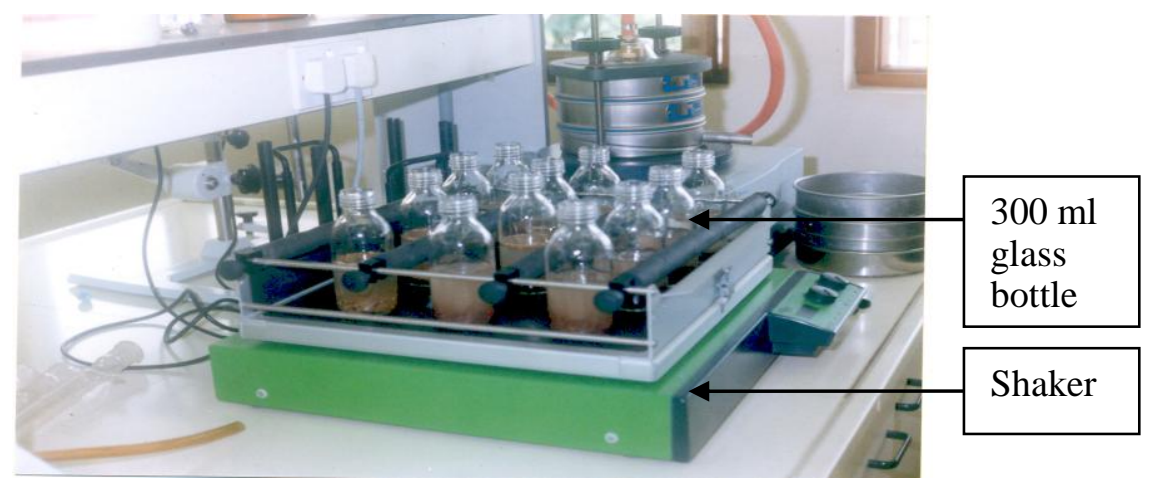

Plate1: Phosphorus sorption experiments in a slow rotating shaker

The analysis of phosphorus sorption behaviours of the substrates involved, determination of Phosphorus sorption isotherms, determination of Phosphorus sorption capacity of the substrates, determination of Phosphorus sorption as the function of time and determination of effect of temperature on the phosphorus sorption.

To determine phosphorus sorption isotherms, twelve $8 \mathrm{~g}$ samples of each substrate grain size (1-2mm, 2$4 \mathrm{~mm}$, and $4-8 \mathrm{~mm}$ ) were suspended in $200 \mathrm{ml}$ of solution containing different phosphorus concentrations $(0,2,4,8,16,20,40,80,160,320$, 600 and $1200 \mathrm{mg}$ P/L). The solutions were filled in $300 \mathrm{ml}$ glass bottles. The bottles with incubated solutions were placed on a 25-rpm shaker for twentyfour hours. The experiment was kept at $8 \mathrm{pH}$ using $\mathrm{NaOH}$ and room temperature $\left(28^{\circ} \mathrm{C}-29^{\circ} \mathrm{C}\right)$. The solutions were filtered with a $0.45 \mu \mathrm{m}$ filter membrane and the filtrates analyzed for phosphorus (APHA, AWWA and WEF, 1998). The phosphorus sorption isotherms (expressed in $\mathrm{mg} \mathrm{P} / \mathrm{Kg}$ substrate) were calculated from the change in the phosphorus concentration of the contact solutions, per mass of the substrate, times the volume of the solution in the flask.

To study phosphorus sorption as a function of time experiment, four $300 \mathrm{ml}$ glass bottles were employed. The bottles were filled with $200 \mathrm{ml}$ solutions containing phosphorus concentration of $20 \mathrm{mg}$ P/L, and $8 \mathrm{~g}$ of substrates. In this experiment, grain sizes used, were $1-2 \mathrm{~mm}$, and $4-8 \mathrm{~mm}$. Then the bottles with incubated solutions were placed on a slow rotating shaker $(25 \mathrm{rpm})$ where contact time was varied from 1 to 300 hours. The experiment was kept at $8 \mathrm{pH}$ 
using $\mathrm{NaOH}$ and room temperature $\left(28^{\circ} \mathrm{C}-29^{\circ} \mathrm{C}\right)$. The solutions were filtered with a $0.45 \mu \mathrm{m}$ filter membrane and the filtrates analyzed for phosphorus (APHA, AWWA and WEF, 1998).

To investigate the effect of temperature on phosphorus sorption, twenty-four $300 \mathrm{ml}$ glass bottles were employed. One $8 \mathrm{~g}$ sample of each substrate grain size $(1-2 \mathrm{~mm}, 2-4 \mathrm{~mm}$, and $4-8 \mathrm{~mm})$ were suspended in $200 \mathrm{ml}$ of solution with phosphorus concentration of $30 \mathrm{mg} \mathrm{P} / \mathrm{L}$ The experiment was conducted at $35^{\circ} \mathrm{C}$ water bath (Julabo type, ECO Temp TW8, German), and at $21^{\circ} \mathrm{C}, 40^{\circ} \mathrm{C}$, and $45^{\circ} \mathrm{C}$ incubator (WTB binder type, model 720, German) for twenty-four hours. The experiment was kept at $8 \mathrm{pH}$ $\mathrm{pH}$ using $\mathrm{NaOH}$. The solutions were filtered with a $0.45 \mu \mathrm{m}$ filter membrane and the filtrates analyzed for phosphorus (APHA, AWWA and WEF, 1998).

Statistical Validity of Data: For all treatments in the experiment, four replicates were used. The data used in all the discussion are the mean values of the four replicates. ANalysis of VAriance (ANOVA) and Regression analysis was performed.

For ANOVA statistical test, a single test was performed to see if there are significant difference on phosphorus sorption between the three grain sizes (1$2 \mathrm{~mm}, 2-4 \mathrm{~mm}$ and 4-8 $\mathrm{mm}$ ) of the Moshi Pumice substrate at $95 \%$ Confidence Interval (0.05 probability level).

Linear Regression analysis was used for determining the relationship between, the amount of phosphorus sorbed by the substrate and phosphorus concentration, the amount of phosphorus sorbed by the substrate and temperature and the amount of phosphorus sorbed by the substrate and time.

\section{RESULTS AND DISCUSSION}

The physical properties and chemical composition of the substrates are presented in Table 1 and Table 2, respectively.

Table 1: Physical Characteristics of Moshi Pumice Substrate

\begin{tabular}{lllll}
\hline $\begin{array}{l}\text { Average particle } \\
\text { diameter }(\mathrm{mm})\end{array}$ & $\begin{array}{l}\text { Specific surface area, } \\
\left(\mathrm{mm}^{2} / \mathrm{g}\right)\end{array}$ & Porosity & $\begin{array}{l}\text { Particle density } \\
\left(\mathrm{kg} / \mathrm{m}^{3}\right)\end{array}$ & $\mathrm{pH}$ \\
1 & 13.35 & $66 \%$ & 2617 & 7.9 \\
\hline
\end{tabular}

Table 2: Chemical Composition of Moshi Pumice Substrate

\begin{tabular}{|c|c|c|c|c|c|c|c|c|c|}
\hline $\begin{array}{c}\mathrm{Al}_{2} \mathrm{O}_{3} \\
\%\end{array}$ & $\begin{array}{c}\mathrm{CaO} \\
\%\end{array}$ & $\begin{array}{r}\mathrm{MgO} \\
\%\end{array}$ & $\begin{array}{c}\mathrm{Fe}_{2} \mathrm{O}_{3} \\
\%\end{array}$ & $\begin{array}{c}\mathrm{MnO} \\
\%\end{array}$ & $\left(\mathrm{Na}_{2} \mathrm{O}+\mathrm{K}_{2} \mathrm{O}\right) \%$ & $\begin{array}{c}\mathrm{SiO}_{2} \\
\%\end{array}$ & $\begin{array}{c}\mathrm{P}_{2} \mathrm{O}_{5} \\
\%\end{array}$ & $\begin{array}{c}\mathrm{TiO}_{2} \\
\%\end{array}$ & $\begin{array}{r}\text { LOI } \\
\%\end{array}$ \\
\hline 19.2 & 1.3 & 0.69 & 5.13 & 0.05 & 6.7 & 61.9 & 0.04 & 0.51 & 4.4 \\
\hline
\end{tabular}

As presented in Table 1, the analyzed physical properties of the substrate were specific surface area, porosity, $\mathrm{pH}$ and Particle diameter and density. The specific surface area and porosity are an indirect measure of the surface available for the adsorption of phosphorus although it depends also on the density of the active sites on the material.

As presented in Table 2, the analysis shows that Moshi Pumice substrate has high levels of Al and Si. The high levels of $\mathrm{Al}$ and $\mathrm{Si}$ are the positive indicator of its potential for phosphorus precipitation.
The phosphorus sorption isotherms obtained for different Moshi Pumice grain sizes are presented in Figure 1. Above $400 \mathrm{mg} \mathrm{P} / \mathrm{L}$, the sorption curves showed no significant change indicating that the maximum sorption capacity of the substrate has been reached. According to this analysis, the maximum sorption capacities for the substrate were $2500 \mathrm{mg}$ $\mathrm{P} / \mathrm{Kg}, 2200 \mathrm{mg} \mathrm{P} / \mathrm{Kg}$ and $2100 \mathrm{mg} \mathrm{P} / \mathrm{Kg}$ for the grains 1-2 mm, 2-4 $\mathrm{mm}$ and $4-8 \mathrm{~mm}$, respectively. 


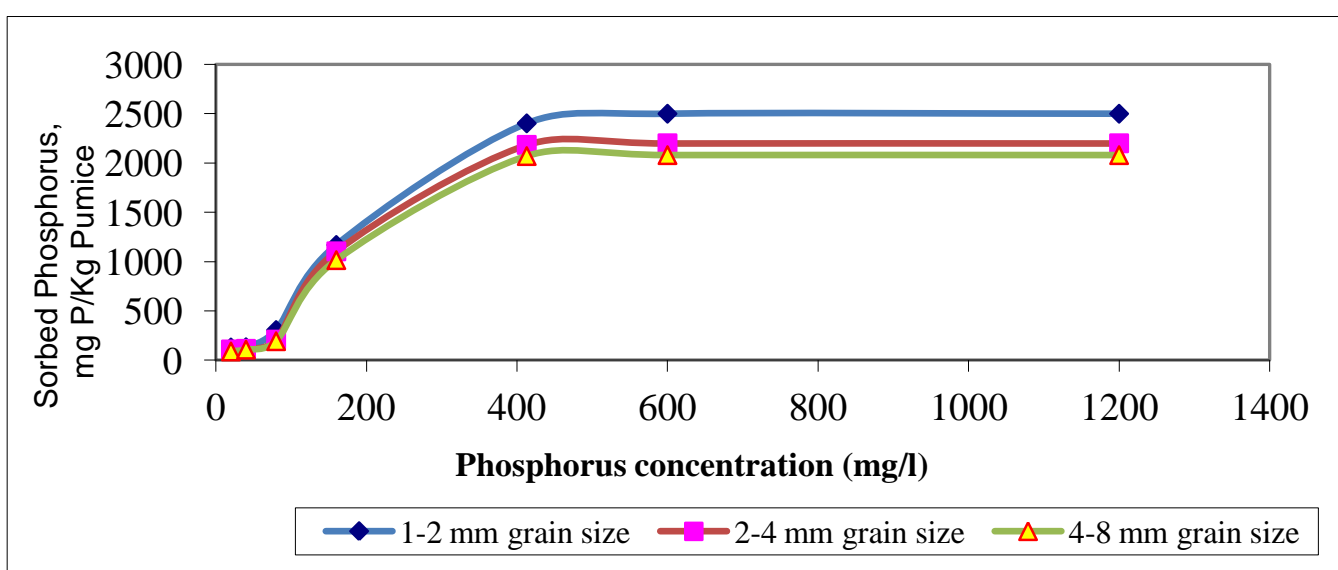

Figure 1: The Phosphorus Sorption Isotherms for Moshi Pumice Substrate

The tabulated value of $\mathrm{F}$ at $95 \%$ Confidence Interval is 4.3. The calculated $F$ value $(F=192397.43)$ exceeds this tabulated $\mathrm{F}$ value $(\mathrm{F}=4.3)$ at $95 \%$ Confidence Interval. So there is a significant difference between in phosphorus sorption between Moshi Pumice grains (i.e. 1-2 mm, 2-4 mm and 4-8 $\mathrm{m})$.

Freundlich model is useful for describing physical sorption. The model can represent non linear sorption of phosphorus from solution. The model equation is exponential and is represented by equation (1) (Volesky

$$
Q=K C^{\frac{1}{n}}
$$

where, $\mathrm{Q}=$ the amount sorbed $\mathrm{C}=$ equilibrium concentration, $\mathrm{mg} / \mathrm{L} \mathrm{K}=$ dimensionless Freundlich constant, indicator of the sorption capacity. $\mathrm{n}=$ dimensionless Freundlich constant, indicator of the sorption intensity. The sorption $(\mathrm{Q})$ to concentration (C) relationship by Freundlich model is presented in Figure 2 and equations 2-4.

$$
\begin{aligned}
& 1-2 m m: \log (\mathrm{Q})=0.807 \log (\mathrm{C})+1.169 \\
& \mathrm{R}^{2}=0.945 \\
& 2-4 m m: \log (\mathrm{Q})=0.887 \log (\mathrm{C})+0.916 \\
& \mathrm{R}^{2}=0.944 \\
& 4-8 m m: \log (\mathrm{Q})=0.989 \log (\mathrm{C})+0.626 \\
& \mathrm{R}^{2}=0.952
\end{aligned}
$$

Sampling during the first day and increasing the incubation time to 360 hours obtained a curve. Figure

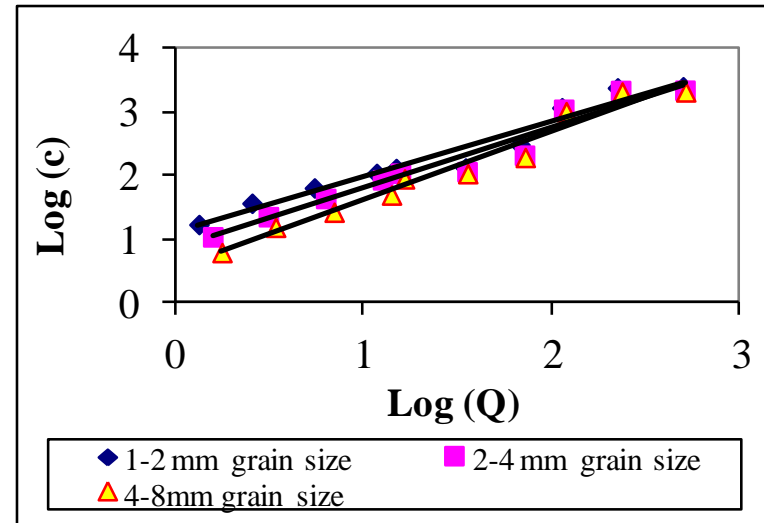

Figure 2: Fitting Moshi Pumice's Sorption Data with Freundlich Model

Since the relationship of $\log (\mathrm{Q}) \& \log (\mathrm{C})$ is linear with a maximum of $\mathrm{R}^{2}=0.9$, it indicates that the Freundlich model fitted all the sorption isotherms data quite satisfactorily hence the correlations are acceptable and the model can be use in prediction and verification of the amount of phosphorus sorbed at any equilibrium concentration.

Under the same conditions, the difference between the phosphorus sorption behaviours of the fine and coarse grain is attributed to the large sorbing surface area of the finer medium and the more easily released metal ions in the finer medium. This can be verified by equation 2 where by the grain $1-2 \mathrm{~mm}$ has the highest sorption capacity coefficient $(\mathrm{k}=14.76)$ compared to the others.

3 presents the effect of incubation time on the sorbed phosphorus at different grain sizes of Moshi Pumice 
substrate. For each case concentration of $20 \mathrm{mg} / \mathrm{l}$ of phosphorus was added.

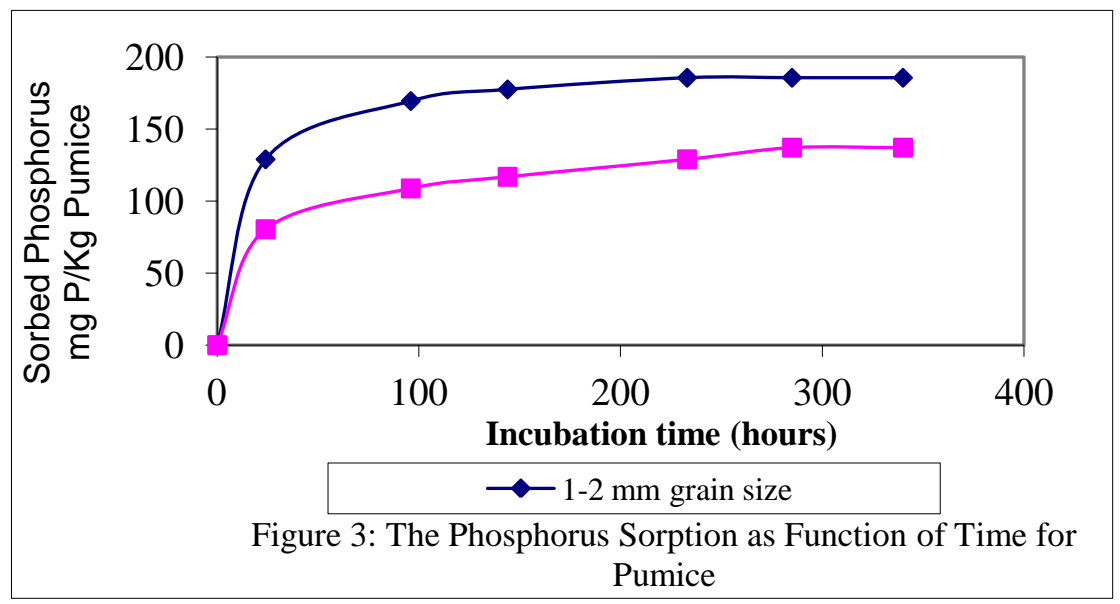

Michaelis-Menten equation was adopted to express the phosphorus sorption as a function of time. The model equation is presented by equation (5).

$$
Q_{(t)}=\left(Q \max ^{*} t\right) /(k+t)
$$

Where, $\mathrm{t}=$ incubation time $(\mathrm{hr}) . \mathrm{Q}_{(t)}=$ the amount of sorbed phosphorus (mg P/Kg substrate) at time t. Qmax $=$ the maximum phosphorus sorption at a certain phosphorus loading ( $\mathrm{mg} \mathrm{P} / \mathrm{Kg}$ substrate). $k=$ constant, when $50 \%$ of the maximum sorption occur.

To determine the constants $k$ and Qmax, the Lineweaver-Bulk analysis method of linearizing substrate-sorption data was used. When the sorption activity follows Michaelis-Menten Model, a reciprocal plot of $1 / \mathrm{Q}$ vs $1 / \mathrm{t}$ is made. From this plot; Y-intercept $=1 / \mathrm{Qmax}, \mathrm{X}$-intercept $=-1 / k$, and slope $=k / \mathrm{Qmax}$. The 1/Q-1/t relationships by LineweaverBulk analysis method for the 1-2 $\mathrm{mm}$ and $4-8 \mathrm{~mm}$ grain sizes of the substrates are presented in Figs 4, while the Q-t relationships by Michaelis-Menten model for the same grain sizes are presented in equations 6-7.

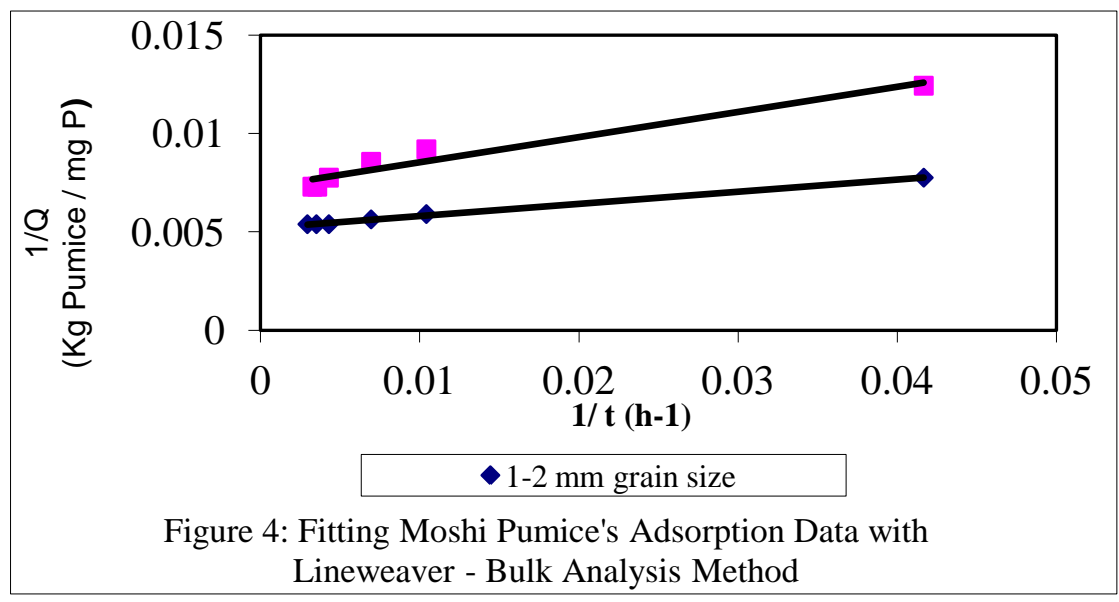

Michaelis-Menten Model Equations for the Moshi Pumice Substrate is as described by equations 6 \& 7

$\begin{array}{ll}(1-2 \mathrm{~mm}): & Q_{(t)}=(192.3 * t) /(11.9+t) \\ (4-8 \mathrm{~mm}): & Q_{(t)}=(137 * t) /(17.4+t)\end{array}$

From equations 6-7, the highest phosphorus sorption of the two tested grain sizes when phosphorus

$$
\begin{aligned}
& r^{2}=0.998 \\
& r^{2}=0.956(7)
\end{aligned}
$$

concentration in the initial solution was $20 \mathrm{mg} / \mathrm{L}$ are 192.3 and $137 \mathrm{mg} \mathrm{P} / \mathrm{Kg}$ Moshi Pumice for the 
grains 1-2 $\mathrm{mm}$ and $4-8 \mathrm{~mm}$ respectively. It took longer time for the course substrate and shorter time for the fine substrate to reach sorption equilibrium. For 1-2 $\mathrm{mm}$ and $4-8 \mathrm{~mm}$ grains, $50 \%$ of the phosphorus sorption in Moshi Pumice substrate occurs in the first 18 and 20 hours, respectively. It takes about 233 hours and 285 hours for $1-2 \mathrm{~mm}$ and 4-8 $\mathrm{mm}$ grains, respectively, to reach the sorption equilibrium when the phosphorus concentration in the initial solution was $20 \mathrm{mg} \mathrm{P} / \mathrm{L}$. The results of effect of temperature on phosphorus sorption are presented in Table 3 and Figure 5.

Table 3: Effect of Temperature on Phosphorus Sorption

\begin{tabular}{lccc}
\hline $\begin{array}{l}\text { Sorbed phosphorus at } \\
\text { different temperatures }\end{array}$ & $1-2 \mathrm{~mm}$ & $2-4 \mathrm{~mm}$ & $4-8 \mathrm{~mm}$ \\
& & & \\
$21^{\circ} \mathrm{C}$ & 101.8 & 81.9 & 63.4 \\
$35^{\circ} \mathrm{C}$ & 120 & 111 & 103.9 \\
$40^{\circ} \mathrm{C}$ & 136.3 & 128.2 & 124 \\
$45^{\circ} \mathrm{C}$ & 152.5 & 144.4 & 140.3 \\
Average Decrease $(\%)$ & 33 & 43 & 57 \\
\hline
\end{tabular}

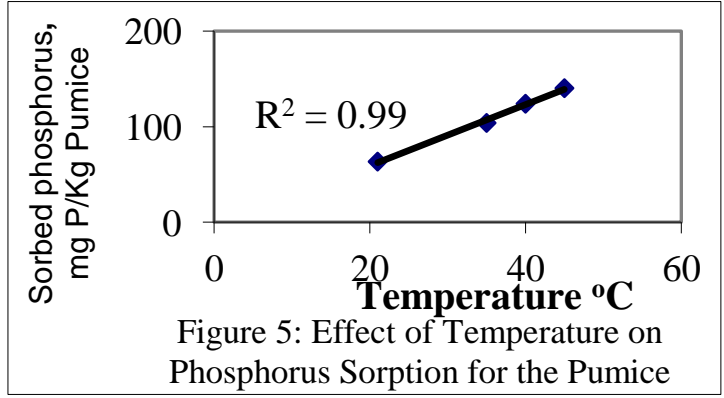

These results show that the phosphorus sorption increases as temperature increases. With the treatment of $20 \mathrm{mg} \mathrm{P} / \mathrm{L}$ in the original incubation solution, a temperature increase from $21^{\circ} \mathrm{C}$ to $45^{\circ} \mathrm{C}$ for the substrate led to an increase in phosphorus sorption of $33 \%, 43 \%$ and $57 \%$ for $1-2 \mathrm{~mm}, 2-$ $4 \mathrm{~mm}$ and $4-8 \mathrm{~mm}$ grains, respectively. The plot of sorbed phosphorus versus temperature gives a linear relationship (Figure 5). High temperatures increase the activity of the metal ion and thus increase the rate of metal ion transfer.

Conclusions and Recommendations: The grain size of the tested Moshi Pumice can influence sorption of phosphorus. The finer the grain sizes the higher the phosphorus sorption. The substrate has high sorption capacity.Since phosphorus concentrations in the sewage are normally in the range of 5-15 mg P/L (Metcalf and Eddy, 1998), the Moshi Pumice substrate will assure that a bed of the substrates can be used for phosphorus removal in sewage for a long duration without being overloaded. From phosphorus sorption as a function of time experiment, it takes longer time (233 hours) for the coarse substrates (4-8 $\mathrm{mm}$ grains) and shorter time (285 hours) for the fine substrates (1-2 $\mathrm{mm}$ grains) to reach sorption equilibrium. Fine substrates has high removal rate. There was an effect of temperature on phosphorus sorption. Temperature has higher effect on the course size than the finer size. As the temperature increases the sorption of phosphorus increases. Based on the studies and tests carried out, the substrate has high potential in phosphorus removal. It can be recommended to be used as a substrate in constructed wetlands to remove phosphorus.

Acknowledgements: I would like to express my special thanks and appreciation to all those who helped me in completion of this research work. I would like to give my special thanks and appreciation to my supervisors, Prof. T.S.A. Mbwette and Prof. K.N Njau for giving me support, advice and comments during the conduct of this research.

\section{REFERENCES}

APHA, AWWA and WEF (1998). Standard Methods for Examination of Water and Wastewater. American Public Health Association, American Water Works Association and Water Environment Federation, Washington D.C.

Braskerud, B. C. (2002). Factors affecting phosphorus retention in small constructed wetlands treating agricultural non-point source pollution. Ecological Engineering 19:41-61.

Headley, T.R., Huett, D.O. and Davison, L. (2001). The removal of nutrients from plant nursery irrigation runoff in subsurface horizontal-flow wetlands. Water Sci. Technology 44 (11).

Metcalf and Eddy, Inc. (1998). Wastewater Engineering: Treatment, Disposal and Reuse. McGraw-Hill Inc., New York, N.Y.

Njau, K.N., Minja, R.J.A., Katima, J.H.Y. ( 2002). Pumice soil: A potential wetland substrate for treatment of domestic wastewater. Proceedings, $8^{\text {th }}$ international conference on wetlands systems for water pollution control in Arusha Tanzania 1: 290-303.

Volesky B. (1999). "Evaluation of sorption performance". Biotechnol Progress 11: 235-50.

Maehlum, T., Jenssen, P.D., Krogstad, T. ( 2002). Phosphorus sorption characteristics of light weight aggregate. Proceedings, $8^{\text {th }}$ international conference on wetlands systems for water pollution control in Arusha Tanzania 1: 556-566. 